\title{
Compost, bokashi y microorganismos eficientes: sus beneficios en cultivos sucesivos de brócolis
}

\author{
Compost, bokashi and efficient microorganisms: \\ their benefits in successive crops of broccoli \\ Nain Peralta-Antonio ${ }^{1 *}$, Gilberto Bernardo de Freitas ${ }^{2}$, \\ Maristela Watthier ${ }^{3}$, Ricardo Henrique Silva Santos ${ }^{2}$
}

\section{RESUMEN}

Compost, bokashi y microorganismos eficientes (EM) son alternativas viables para la nutrición de los cultivos agrícolas producidos de forma orgánica. Su aplicación afecta al primer cultivo y a cultivos subsecuentes. El objetivo fue evaluar el efecto de compost, bokashi y EM en el crecimiento, producción de materia fresca y materia seca en dos cultivos de brócolis consecutivos. En el primer cultivo de brócoli se aplicó: $19 \mathrm{t} \mathrm{ha}^{-1}$ de compost (C19), $19 \mathrm{t} \mathrm{ha}^{-1}$ compost + EM $2 \%$ (C19+EM2), $15 \mathrm{t} \mathrm{ha}^{-1}$ compost $+2 \mathrm{t} \mathrm{ha}^{-1} \mathrm{de}$ bokashi (15C+B2), EM 2\% (EM2), $10 \mathrm{t} \mathrm{ha}^{-1}$ de bokashi (B10) y testigo sin fertilización (TSF). En el segundo cultivo de brócoli se evaluó el efecto residual de los tratamientos sin realizar ninguna fertilización adicional. Similar área de dosel se observó entre tratamientos en el primer y segundo cultivo de brócolis. Con C19, C19+EM2 y B10 se obtuvo mayor cantidad de materia seca en comparación con TSF. En el primer cultivo de brócoli, el tratamiento con mayor rendimiento fue C19+EM2. El efecto residual de los tratamientos fue mayor en B10 al promover mayor producción de materia fresca del tallo en comparación con EM y TSF. La fertilización orgánica no afectó el crecimiento de las plantas en el primer y segundo cultivo. Fertilización exclusiva de compost y bokashi, aplicado solo o en conjunto promueven mayor materia fresca que plantas no fertilizadas, en el primer cultivo. EM potencia el efecto del compost, pues su aplicación conjunta estimula mayor materia fresca y materia seca que plantas no fertilizadas, en el primer cultivo. En los suelos con fertilidad media o alta, el compost aplicado solo o en conjunto con bokashi o EM sólo tiene efecto a corto plazo, pues no promovió efecto residual en el segundo cultivo de brócoli.

Palabras clave: Brassica oleracea L. var. itálica, Agricultura orgânica, Biomassa microbiana, Ciclo fenológico.

\begin{abstract}
Compost, bokashi and efficient microorganisms (EM) are viable alternatives for the nutrition of agricultural crops produced of organic form. Its application affects the first crop and subsequent crops. The objective was to evaluate the effect of compost, bokashi and EM on the growth, production of fresh matter and dry matter in two consecutive broccoli crops. In the first broccoli

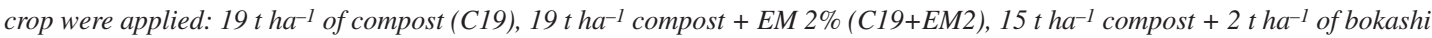
(15C+B2), EM 2\% (EM2), $10 t \mathrm{ha}^{-1}$ of bokashi (B10) and control without fertilization (CWF). In the second crop broccoli the residual effect was evaluated, without additional fertilization. Similar canopy area was observed between treatments in the first and second broccoli crop. Greater amount of dry matter was obtained with C19, C19+EM2 and B10 in comparison with CWF. In the first broccoli crop the treatment with highest amounts of dry matter was C19+EM2. The residual effect of treatments was greater with B10 because promoted higher stem fresh matter compared to EM2 and CWF. The organic fertilization did not affect the growth of plants in the first and second broccoli crop. Exclusive fertilization of compost and bokashi, applied alone or together, promote greater fresh matter than unfertilized plants in the first broccoli crop. EM potentiates the effect of the compost, since its joint application stimulates more fresh matter and dry matter than unfertilized plants in the first crop. In soils with medium or high fertility, compost applied alone or in conjunction with bokashi or EM only has a short-term effect, as they did not promote residual effect in the second broccoli crop.
\end{abstract}

Key words: Brassica oleracea L. var. itálica, Organic agriculture, Microbial biomass, Phenological cycle.

$1 \quad$ Instituto Nacional de Investigaciones Forestales Agrícolas y Pecuarias (INIFAP), km 34.5 Carretera Federal VeracruzCórdoba, Medellín, Ver. Méx. C.P. 91700.

2 Profesor del Departamento de Fitotecnia - Universidade Federal de Viçosa, Campus Universitário Viçosa, CEP 36570-000, Viçosa, MG.

3 Fundação Luterana de Diaconia, Centro de Apoio e promoção da Agroecologia - Pelotas, RS, 96010-140, Brazil.

* * Autor por correspondencia: peralta.nain@inifap.gob.mx; peraltanain@gmail.com

Fecha de Recepción: 11 Julio, 2018.

Fecha de Aceptación: 15 Enero, 2019. 


\section{Introducción}

Compost y bokashi son fertilizantes orgánicos que fomentan el reciclaje de residuos orgánicos locales, estimulan la creatividad del productor para formular dichos insumos y son alternativas para nutrir a cultivos agrícolas en el sistema de producción orgánica. Diversos estudios han mostrado que la producción de materia seca en los cultivos aumenta, en la medida en que aumenta la dosis de fertilización orgánica, independiente del tipo de fertilizante orgánico utilizado (Ferreira et al., 2013; Herencia y Maqueda, 2016).

Bioestimulantes es una tecnología que ha ganado importancia actualmente. Consiste en la mezcla de microorganismos y sustancias que benefician al crecimiento y producción de los cultivos (Calvo et al., 2014). En el mercado, se puede encontrar en cantidad limitada o con alto precio, dependiendo de la posición geográfica. Esta limitación llevó a investigadores y agricultores a desarrollar una alternativa a los bioestimulantes industriales, basado en la captura de microorganismos locales y reproducidos posteriormente a través del proceso fermentativo. Esta alternativa es denominada como microorganismos eficientes (EM) y consiste en la coexistencia de poblaciones de hongos y bacterias nativas de la región (Bonfim et al., 2011; Santos, 2016). Formulaciones de EM pueden ser utilizadas en la elaboración de fertilizantes orgánicos o aplicados directamente al suelo para acelerar la descomposición de residuos orgánicos. Los efectos positivos de EM ha sido demostrado en frijol de China, al aumentar la biomasa de raíz en comparación con las plantas sin EM (Javaid, 2009). Mayor altura y materia seca de la parte aérea se observó en el segundo ciclo productivo de frijol China (sin realizar una nueva fertilización) en suelos que recibieron EM en comparación con suelos sin EM (Javaid y Mahmood, 2010).

Efectos benéficos también se consiguen al aplicar conjuntamente fertilizante orgánicofertilizante orgánico o fertilizante orgánico-EM. Mayor recuperación y mayor eficiencia de utilización de $\mathrm{N}$ se observó en brócoli con $12 \mathrm{t}$ $\mathrm{ha}^{-1}$ de compost aplicada en conjunto con residuos de Mucuna pruriens (Diniz et al., 2015). Mayor producción de paja, grano y concentración de $\mathrm{N}$, P y K se observó en trigo fertilizado con $15 \mathrm{tha}^{-1}$ de compost en conjunto con EM en comparación con plantas que no recibieron EM y plantas no fertilizadas (Hu y Qi, 2013).
La fertilización puede afectar positivamente el primer cultivo y cultivos subsecuentes, lo que se conoce como efecto residual, que dependerá de las características del suelo, tipo y dosis de fertilizante utilizado y cantidad de nutrientes removidos por el primer cultivo (Diniz et al., 2017; Suarez-Tapia et al., 2018; Vargas et al., 2017).

El objetivo de la investigación fue evaluar el efecto de compost orgánico, bokashi y EM en el crecimiento, producción de materia fresca y materia seca en el primer cultivo de brócoli y el efecto residual de los tratamientos en el segundo cultivo de brócolis.

\section{Material y métodos}

\section{Fertilizantes orgánicos y microorganismos eficientes}

Compost orgánico, bokashi y EM se elaboraron en la Universidad Federal de Viçosa (2045'25,7' S y $42^{\circ} 52^{\prime} 11,9$ " W). Mezcla de cáscara de café, estiércol de gallina y materia fresca de la parte aérea de Gliricidia sepium en una proporción 5,5:1:1 (volumen:volumen) se utilizó para la elaboración del compost (19,9 de relación C/N y $2,09,0,33.0,64,1,17,0,43,0,33$ y $41,7 \mathrm{dag}$ $\mathrm{kg}^{-1}$ de $\mathrm{N}, \mathrm{P}, \mathrm{K}, \mathrm{Ca}, \mathrm{Mg}, \mathrm{S}$ y matéria orgânica, respectivamente). Humedecimiento y aireación a través de removimiento fue realizado mensualmente al compost, durante tres meses. Mezcla de cáscara de café, suelo de bosque nativo, estiércol caprino, salvado de trigo, azúcar y agua, en la proporción 2:1:2:2:2:0,08:1,2 (volumen:volumen) fue utilizado para la elaboración del bokashi $(23,5$ de relación C/N y 2,15, 0,77, 1,23, 1,99, 0,44, 0,39 y 50,6 dag $\mathrm{kg}^{-1}$ de $\mathrm{N}, \mathrm{P}, \mathrm{K}, \mathrm{Ca}, \mathrm{Mg}, \mathrm{S}$ y materia orgánica, respectivamente). El bokashi fue removido una vez al día, hasta alcanzar la temperatura ambiente. microorganismos edáficos fueron capturados en un bosque nativo de la región, donde, arroz cocido fue utilizado como trampa. Los microorganismos eficientes fueron formulados de acuerdo con Bonfim et al. (2011).

\section{Tratamientos}

Los tratamientos (basados en materia seca): 1) Testigo sin fertilización (TSF); 2) $19 \mathrm{t} \mathrm{ha}^{-1} \mathrm{de}$ compost (C19); 3) $19 \mathrm{t} \mathrm{ha}^{-1}$ de compost + EM $2 \%$ (C9+EM2); 4) $15 \mathrm{t} \mathrm{ha}^{-1}$ de compost $+2 \mathrm{t} \mathrm{ha}^{-1} \mathrm{de}$ 
bokashi (C15+B2); 5) microorganismos eficientes al 2\% (EM2); 6) $10 \mathrm{t} \mathrm{ha}^{-1}$ de bokashi (B10) fueron obtenidos con base en las características del suelo (Tabla 1), compost y bokashi. Se aplicó 0, 397, 397, 357,0 y $215 \mathrm{~kg} \mathrm{ha}^{-1}$ de $\mathrm{N}$ a través de TSF, C19, C9+EM2, C15+B2, EM y B10, respectivamente, cantidades que se encuentran dentro de la dosis recomendada para brócolis (Fontes, 1999). La cantidad total de cada fertilizante $(\mathrm{kg})$ fue dividido entre 19444 plantas por hectárea (obtenida con $0,6 \mathrm{~m} \times 0,6 \mathrm{~m}$, en una superficie útil del $70 \%$ de la superficie de una hectárea) para obtener la dosis por planta. Bloques al azar fue el diseño experimental utilizado en el experimento, cada tratamiento con cuatro repeticiones, considerando una planta como unidad experimental.

\section{Brócoli utilizado y su manejo}

Semillas de brócoli de cabeza única, cultivar BRO68 $^{\circledR}$, fueron sembradas en $24 / 06 / 2015$ y $14 / 03 / 2016$ para el primer y segundo cultivo (efecto residual), respectivamente. Plántulas de brócolis fueron trasplantadas a macetas de 30 L (una planta por maceta). Compost y bokashi fueron aplicados en dosis única (mezclado con los primeros $20 \mathrm{cmde}$ profundidad) cinco días antes del trasplante. Aplicaciones semanales de EM 2\% (100 mL por planta) fueron realizadas en la superficie del suelo, desde el trasplante hasta la cosecha de las inflorescencias (en total 10 aplicaciones). El trasplante fue realizado a los 34 y 42 días posteriores a la siembra de las semillas

Tabla 1. Características del suelo utilizado para en el primer cultivo de brócolis de cabeza única $\mathrm{BRO} 68^{\circledR}$.

\begin{tabular}{|c|c|c|c|c|c|c|}
\hline $\mathrm{pH}$ & $\mathrm{MO}$ & $\mathrm{P}$ & $\mathrm{K}$ & $\mathrm{Ca}^{2+}$ & $\mathrm{Mg}^{2+}$ & $\mathrm{Al}^{3+}$ \\
\hline- & $\overline{\text { dag kg-1}}$ & \multicolumn{2}{|c|}{$\mathrm{mg} \mathrm{dm}^{-3}$} & \multicolumn{3}{|c|}{$\mathrm{cmol}_{\mathrm{c}} \mathrm{dm}^{-3}$} \\
\hline 5,1 & 3,49 & 69,9 & 222 & 3,37 & 0,74 & 0,00 \\
\hline $\mathrm{H}+\mathrm{Al}$ & SB & $\mathrm{t}$ & $\mathrm{T}$ & $\mathrm{V}$ & \multirow{2}{*}{\multicolumn{2}{|c|}{$\begin{array}{l}\text { P-Rem } \\
\mathrm{mg} \mathrm{L}^{-1}\end{array}$}} \\
\hline \multicolumn{5}{|c|}{$\mathrm{cmol}_{\mathrm{c}} \mathrm{dm}^{-3}$} & & \\
\hline 3,5 & 4,68 & 4,68 & 8,18 & 57,2 & \multicolumn{2}{|c|}{45,3} \\
\hline
\end{tabular}

$\mathrm{pH}=$ acidez activa; $\mathrm{MO}=$ materia orgánica; $\mathrm{P}=$ fosforo disponible; $\mathrm{K}=$ potasio disponible; $\mathrm{Ca}^{2+}=$ calcio intercambiable; $\mathrm{Mg}^{2+}=$ magnesio intercambiable; $\mathrm{Al}^{3+}=$ acidez intercambiable; $\mathrm{H}+\mathrm{Al}$ $=$ acidez potencial $; \mathrm{SB}=$ suma de bases intercambiable; $\mathrm{t}=$ Capacidad de intercambio catiónico efectiva; $\mathrm{T}=$ Capacidad de intercambio catiónico efectiva a pH 7,0; V = Índice de saturación de bases; P-rem = fosforo remaneciente. en el primer y segundo cultivo, respectivamente. Riegos manuales fueron realizados según la necesidad de la planta (sin recuperación del agua drenada de las macetas). Datos de clima e insolación fueron registrados durante todo el experimento (Figura 1).

\section{Área de dosel, producción de materia fresca y materia seca}

El área del dosel (calculado a partir de la medida superior del dosel en sentido longitudinal y transversal a la fila de siembra) se utilizó como parámetro para medir el crecimiento del brócoli (cada 15 días) en los dos cultivos, inició en el momento del trasplante y concluyó a los 45 días después del trasplante.

Cuantificación de la materia fresca del brócoli (tallo, hoja, pecíolo e inflorescencia) se realizó al momento de la cosecha (en los dos cultivos). Las inflorescencias fueron cortadas (cuando alcanzaron el punto de cosecha) a 2,5 $\mathrm{cm}$ por debajo del último miniflorete. Muestras de cada órgano fueron colocadas en estufa de secado forzado a $40^{\circ} \mathrm{C}$ para obtener el peso de materia seca de cada órgano y con la sumatoria de todos los órganos se obtuvo la materia seca total.

\section{Análisis de datos}

Análisis de variancia y pruebas de medias de Tukey $(\mathrm{p}<0,05)$ fue realizado para todas las variables con auxilio del programa estadístico SAS 9,0.

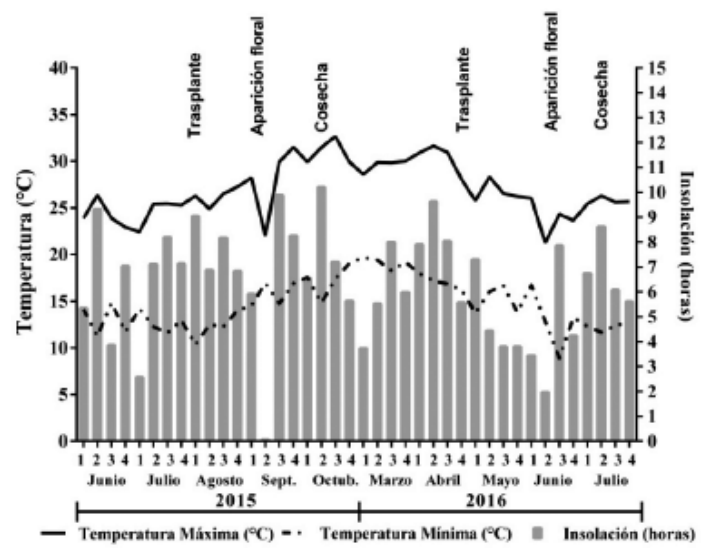

Figura 1. Temperatura máxima y mínima del aire y horas de insolación durante los meses en que fueron desarrollados dos ciclos productivos de brócoli de cabeza única BRO6 $8^{\circledR}$ en Viçosa, Minas Gerais, Brasil. 


\section{Resultados y discusión}

\section{Área de dosel del primer y segundo cultivo de brócolis}

A los 45 días después del trasplante, el área del dosel de las plantas se mantuvo entre 50 y 63 $\mathrm{dm}^{2}$ en el primer cultivo y entre 71 y $79 \mathrm{dm}^{2}$ en el segundo cultivo, sin existir diferencias entre tratamientos en ninguno de los dos cultivos (Figura 2).

Máxima área foliar se ha observado en otras variedades entre los 56 y 84 días después del trasplante (Francescangeli et al., 2007), por lo que, la ausencia de diferencias entre tratamientos en esta investigación se atribuye a que las plantas aún no habían alcanzado su máximo crecimiento de hojas a los 45 días después del trasplante. Menor área de dosel en el primer cultivo en todos los tratamientos, comparada con el segundo cultivo, se explica por las condiciones de luz solar y la temperatura. Mayor temperatura y mayor insolación (entre 6,5 y 10 horas diarias) en el primer cultivo, debió estimular a que las hojas adoptasen una posición más vertical como una medida para disminuir la captación de luz, situación que cambió para el segundo cultivo, donde, menor temperatura y menor horas de insolación (entre 2 y 9 horas diarias) resultaron en posición de hojas más horizontal como estrategia para captar mayor radiación fotosintéticamente activa (Francescangeli et al., 2007).

La temperatura determina la fecha de la iniciación floral del brócoli y consecuentemente afecta el tiempo del ciclo productivo (Kaluzewicz et al., 2010), que a su vez afectará el tamaño de la planta. En este trabajo la temperatura del aire influenció la duración de ciclo fenológico del

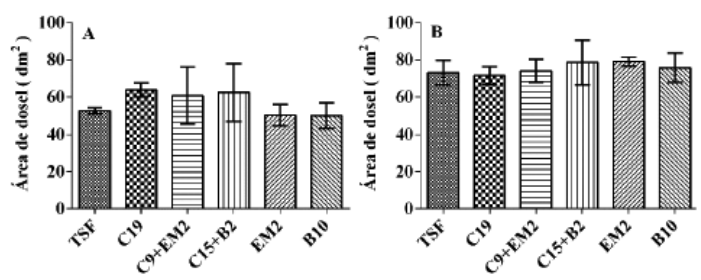

Figura 2. Área de dosel del primer (A) y segundo (B) cultivo de brócoli, manejados sin fertilización (TSF) y fertilizados con 19 t ha $^{-1}$ de compost orgánico (C19); 19 t ha ${ }^{-1}$ de compost orgánico + microorganismos eficientes al 2\% (C19+EM2); $15 \mathrm{t} \mathrm{ha}^{-1}$ de compost orgánico $+2 \mathrm{t} \mathrm{ha}^{-1}$ de bokashi $(\mathrm{C} 15+\mathrm{B} 2)$, microorganismos eficientes $2 \%$ (EM2) e $10 \mathrm{t} \mathrm{ha}^{-1}$ de bokashi (B10). brócoli. Ciclo fenológico de 107 y 134 días se registró para el primer (invierno-primavera) y segundo (otoño-invierno) cultivo, respectivamente. Temperaturas crecientes desde el trasplante hasta la cosecha de las inflorescencias se presentaron en el primer cultivo (de $22^{\circ} \mathrm{C}$ aumentó a $32,6^{\circ} \mathrm{C}$ ), situación contraria ocurrió en el segundo ciclo productivo, donde, temperatura decreciente se observó desde el trasplante hasta la cosecha (de $30,9^{\circ} \mathrm{C}$ disminuyó a $21,1^{\circ} \mathrm{C}$ ) (Figura 1). Menor temperatura resultó en mayor ciclo del cultivo pues las plantas necesitaron más días para alcanzar su requerimiento térmico (Tan et al., 2000), en consecuencia, mayor tamaño de plantas.

\section{Materia fresca y materia seca del primer cultivo de brócoli}

Se demostró el efecto de la fertilización orgánica en el primer cultivo. Mayor materia fresca de los órganos (excepto del pecíolo) y materia fresca total se observó en plantas manejadas con C19, C19+EM2 y B10 en comparación con TSF. Mayor materia fresca de hoja y materia fresca total se observó en C19, C19+EM2 y B10 en comparación con EM2. Mayor materia fresca de hoja y materia fresca total se encontró con C15+B2 en comparación con TSF (Tabla 2). La materia seca fue influenciada por el compost y EM. Mayor materia seca de tallo se observó con C19 y C19+EM en comparación con TSF. Mayor materia seca total se encontró con C19+EM2 en comparación con TSF (Tabla 2).

Mayor materia fresca en plantas manejadas con C19, C19+EM2 y B10 se atribuyen a la cantidad de materia orgánica aplicada, resultando en mayor disponibilidad de agua para la planta (por la mayor área superficial específica del suelo) y menor temperatura del suelo en las horas más calientes del día, reduciendo la transpiración y el estrés térmico (Frasier et al., 2016). El efecto de la fertilización sobre la producción de materia seca ocurre principalmente en suelos con deficiencia nutrimental, donde, pequeños aumentos de un nutriente en el suelo se reflejan en el incremento proporcional de la concentración de ese nutriente en la biomasa y en la producción de materia seca. Ya en suelos con buen nivel de fertilidad el incremento de un nutriente en la solución del suelo, será reflejado en la mayor concentración del nutriente la biomasa de la planta sin que ocurra 
Tabla 2. Materia fresca y materia seca del primer cultivo de brócoli de cabeza única BRO68 ${ }^{\circledR}$ manejado con diferentes fertilizantes orgánicos y con microorganismos eficientes (EM).

\begin{tabular}{|c|c|c|c|c|c|}
\hline \multirow{2}{*}{ Tratamientos } & Hoja & Pecíolo & Tallo & Inflorescencia & Planta total \\
\hline & \multicolumn{5}{|c|}{ Materia fresca $\left(\mathrm{g} \mathrm{planta}^{-1}\right)$} \\
\hline 1. TSF & $219,9 \mathrm{c}$ & $224,0 \mathrm{a}$ & $196,0 \mathrm{~b}$ & $209,5 \mathrm{~b}$ & $849,6 \mathrm{~d}$ \\
\hline 2. C19 & $308,6 \mathrm{a}$ & $271,6 \mathrm{a}$ & $246,6 \mathrm{a}$ & 299,6 a & $1126,5 \mathrm{ab}$ \\
\hline 3. C19+EM2 & $332,3 \mathrm{a}$ & 296,4 a & $252,5 \mathrm{a}$ & 286,1 a & 1167,4 a \\
\hline 4. $\mathrm{C} 15+\mathrm{B} 2$ & $283,2 \mathrm{ab}$ & $258,5 \mathrm{a}$ & $216,6 \mathrm{ab}$ & $242,6 \mathrm{ab}$ & $1001,0 \mathrm{bc}$ \\
\hline 5. EM2 & $238,9 \mathrm{bc}$ & $235,5 \mathrm{a}$ & $219,0 \mathrm{ab}$ & $246,0 \mathrm{ab}$ & $939,5 \mathrm{~cd}$ \\
\hline 6. B10 & 305,0 a & $293,7 \mathrm{a}$ & $247,0 \mathrm{a}$ & 309,0 a & $1154,8 \mathrm{a}$ \\
\hline DMS & 54,1 & 79,9 & 44,0 & 69,7 & 132,0 \\
\hline \multirow[t]{2}{*}{$\mathrm{CV}(\%)$} & 8,3 & 13,2 & 8,3 & 11,4 & 5,9 \\
\hline & \multicolumn{5}{|c|}{ Materia seca ( g planta $\left.^{-1}\right)$} \\
\hline 1. TSF & $48,0 \mathrm{a}$ & $29,5 \mathrm{a}$ & $23,9 \mathrm{~b}$ & $22,7 \mathrm{~b}$ & $124,2 \mathrm{~b}$ \\
\hline 2. C19 & $58,7 \mathrm{a}$ & $31,1 \mathrm{a}$ & $32,9 \mathrm{a}$ & $33,6 \mathrm{ab}$ & $156,5 \mathrm{ab}$ \\
\hline 3. C19+EM2 & $64,6 \mathrm{a}$ & $32,7 \mathrm{a}$ & $32,8 \mathrm{a}$ & $39,1 \mathrm{a}$ & $169,2 \mathrm{a}$ \\
\hline 4. $\mathrm{C} 15+\mathrm{B} 2$ & $65,6 \mathrm{a}$ & $30,5 \mathrm{a}$ & $26,8 \mathrm{ab}$ & $26,7 \mathrm{ab}$ & $149,5 \mathrm{ab}$ \\
\hline 5. EM2 & $51,4 \mathrm{a}$ & $29,2 \mathrm{a}$ & $26,8 \mathrm{ab}$ & $26,2 \mathrm{ab}$ & $133,5 \mathrm{ab}$ \\
\hline 6. B10 & $53,7 \mathrm{a}$ & $33,2 \mathrm{a}$ & $29,6 \mathrm{ab}$ & $32,5 \mathrm{ab}$ & $149,0 \mathrm{ab}$ \\
\hline DMS & 20,7 & $14,2 \mathrm{a}$ & 8,8 & 15,9 & 42,6 \\
\hline $\mathrm{CV}(\%)$ & 15,8 & 19,9 & 13,4 & 22,9 & 12,6 \\
\hline
\end{tabular}

$\mathrm{TSF}=$ testigo sin fertilización; $\mathrm{C} 19=19 \mathrm{t} \mathrm{ha}^{-1}$ de compost orgánico; $\mathrm{C} 19+\mathrm{EM} 2=19 \mathrm{t} \mathrm{ha}^{-1}$ de compost orgánico + microorganismos eficientes al $2 \%(\mathrm{EM} 2) ; \mathrm{C} 15+\mathrm{B} 2=15 \mathrm{t} \mathrm{ha}^{-1}$ de compost orgánico + $2 \mathrm{t} \mathrm{ha}^{-1}$ de bokashi; EM2 = microorganismos eficientes $2 \%$; B10 $=10 \mathrm{tha}^{-1}$ de bokashi; DMS = diferencia mínima significativa; $\mathrm{CV}=$ coeficiente de variación. Medias con la misma dentro de la columna son iguales por la prueba de Tukey $(\mathrm{p}<0,05)$.

aumento en la producción de materia seca (Siddiqi y Glass, 1981). Similar materia seca producida en plantas no fertilizadas y plantas fertilizadas con C19, C15+B2, EM2 y B10, se atribuye al nivel de fertilidad del suelo. Aunque el suelo fue clasificado inicialmente con acidez activa y acidez potencial media, no presentó acidez intercambiable y presentó nivel medio de $\mathrm{Mg}^{2+}$, buenos niveles de materia orgánica y $\mathrm{Ca}^{2+}$, buena capacidad de intercambio catiónico y niveles muy buenos de P y K (Alvarez et al., 1999), demostrando que la aplicación de 397, 356,5 y $215 \mathrm{~kg} \mathrm{ha}^{-1}$ de $\mathrm{N}$ suministrado con la aplicación de compost y bokashi, no necesariamente reflejará mayor rendimiento y producción de materia seca. Los resultados también demostraron que la captura y reproducción de microorganismos nativos es un recurso viable para la producción de brócoli, debido a que, la aplicación de EM potenció el efecto del compost, pues, la materia seca obtenida con C19+EM fue el único tratamiento que superó a las plantas no fertilizadas. Beneficios del EM se pueden atribuir a la mayor absorción de nutrientes, lo que estimula mayor producción de materia seca (Hu y Qi, 2013). Microorganismos eficientes obtenidos de la Mata Atlántica, en la misma región donde fue desarrollado esta investigación, fueron constituidos por bacterias de los filos de Actinobacteria, Firmicutes (principalmente Lactobacillus), Proteobacteria (sobresalió la familia Pseudomonadaceae) y Synergistetes y hongos del género Uwebraunia, Penicillium y Fursarium (Santos, 2016). Estos microorganismos exógenos aplicados al suelo pueden producir ácidos orgánicos, fitohormonas y enzimas extracelulares (Barka et al., 2015; Bolívar-Anillo et al., 2016), que actúan sobre los residuos orgánicos para obtener nutrientes requeridos por la biomasa microbiana y durante ese proceso de descomposición y mineralización se liberan diversos nutrientes a la solución del suelo. Aplicaciones semanales de EM debió aumentar la población microbiana edáfica, lo que, aceleró la velocidad de mineralización y cantidad de nutrientes liberados a la solución del suelo en comparación con los suelos que únicamente recibieron materia orgánica (Ndona et al., 2011). 


\section{Materia fresca y materia seca del segundo cultivo de brócoli (efecto residual)}

El efecto residual de los tratamientos de fertilización se evidenció en la materia fresca del tallo. Plantas fertilizadas con B10 superaron a las fertilizadas con EM y TSF (Tabla 3).

El efecto residual depende de la cantidad de nutriente suministrada, cantidad de nutriente removido por la primera cultura, cantidad de nutriente remanente en el suelo y necesidad nutricional del siguiente cultivo (Diniz et al., 2017, Suarez-Tapia et al., 2018, Suthamathy y Seran 2013). Aunque existen relatos del efecto residual del compost y bokashi, aplicados solos o en conjunto con otros abonos orgánicos (Suthamathy y Seran, 2013), en esta investigación no ocurrió tal resultado. La ausencia de efecto residual en esta investigación demuestra que el efecto de las aplicaciones de compost y bokashi en el rendimiento de inflorescencia y en la producción de materia seca es a corto plazo y se puede relacionar con las características del suelo y remoción de nutrientes en el primer cultivo. El suelo utilizado se clasificó con buen nivel de fertilidad (entre fertilidad media y alta), sugiriendo que este suelo tiene la capacidad de sostener el crecimiento y la producción del brócoli en un segundo cultivo. Se ha documentado rápida mineralización de $\mathrm{C}$ e $\mathrm{N}$, cuando los fertilizantes orgánicos se incorporan al suelo y hay humedad y temperatura adecuada (Diniz et al., 2016). En el presente estudio los abonos orgánicos fueron incorporados y mezclados en los primeros $20 \mathrm{~cm}$ de profundidad del suelo, hubo humedad en el suelo y alta temperatura durante el primer cultivo, por lo que, se presume rápida descomposición de los residuos orgánicos y rápida mineralización de los nutrientes. Mayor disponibilidad de nutriente resultó en mayor cantidad de nutrientes absorbidos en las plantas fertilizadas, principalmente en aquellas que recibieron EM. De esa forma, parte de los nutrientes aplicados con la fertilización fue retirada del suelo durante la cosecha de la planta entera.

Tabla 3. Efecto residual diferentes fertilizantes orgánicos y microorganismos eficientes (EM) (aplicados inicialmente en el primer cultivo de brócoli) sobre la producción de materia fresca y materia seca del segundo cultivo de brócoli de cabeza única BRO68 ${ }^{\circledR}$.

\begin{tabular}{lccccr}
\hline \multirow{2}{*}{ Tratamientos } & Hoja & Pecíolo & Tallo & Inflorescencia & Planta total \\
\cline { 2 - 6 } & \multicolumn{5}{c}{ Materia fresca $\left(\right.$ g planta $\left.^{-1}\right)$} \\
\hline 1. TSF & $243,8 \mathrm{a}$ & $243,9 \mathrm{a}$ & $230,2 \mathrm{~b}$ & $264,5 \mathrm{a}$ & $982,6 \mathrm{a}$ \\
2. C19 & $257,0 \mathrm{a}$ & $249,9 \mathrm{a}$ & $225,2 \mathrm{~b}$ & $313,2 \mathrm{a}$ & $1045,5 \mathrm{a}$ \\
3. C19+EM2 & $290,4 \mathrm{a}$ & $285,8 \mathrm{a}$ & $248,9 \mathrm{ab}$ & $319,6 \mathrm{a}$ & $1144,9 \mathrm{a}$ \\
4. C15+B2 & $284,4 \mathrm{a}$ & $261,5 \mathrm{a}$ & $232,9 \mathrm{ab}$ & $281,4 \mathrm{a}$ & $1060,4 \mathrm{a}$ \\
5. EM2 & $241,9 \mathrm{a}$ & $236,4 \mathrm{a}$ & $217,6 \mathrm{~b}$ & $245,4 \mathrm{a}$ & $941,4 \mathrm{a}$ \\
6. B10 & $307,2 \mathrm{a}$ & $287,8 \mathrm{a}$ & $272,5 \mathrm{a}$ & $381,7 \mathrm{a}$ & $1249,3 \mathrm{a}$ \\
DMS & 66,4 & 95,6 & 40,6 & 189,1 & 332,5 \\
CV $(\%)$ & 10,6 & 15,9 & 7,4 & 27,3 & 13,5 \\
\hline & & & Materia seca $(\mathrm{g}$ planta-1) & \\
\hline 1. TSF & $40,9 \mathrm{a}$ & $24,8 \mathrm{a}$ & $26,4 \mathrm{a}$ & $29,1 \mathrm{a}$ & $121,4 \mathrm{a}$ \\
2. C19 & $38,1 \mathrm{a}$ & $20,2 \mathrm{a}$ & $24,1 \mathrm{a}$ & $30,4 \mathrm{a}$ & $112,9 \mathrm{a}$ \\
3. C19+EM2 & $45,6 \mathrm{a}$ & $26,1 \mathrm{a}$ & $27,9 \mathrm{a}$ & $31,3 \mathrm{a}$ & $131,0 \mathrm{a}$ \\
4. C15+B2 & $48,9 \mathrm{a}$ & $26,1 \mathrm{a}$ & $27,2 \mathrm{a}$ & $30,3 \mathrm{a}$ & $132,5 \mathrm{a}$ \\
5. EM2 & $42,0 \mathrm{a}$ & $23,3 \mathrm{a}$ & $24,9 \mathrm{a}$ & $24,8 \mathrm{a}$ & $114,3 \mathrm{a}$ \\
6. B10 & $44,3 \mathrm{a}$ & $24,4 \mathrm{a}$ & $28,7 \mathrm{a}$ & $38,4 \mathrm{a}$ & $135,9 \mathrm{a}$ \\
DMS & 14,9 & 8,0 & 4,6 & 15,8 & 33,4 \\
CV (\%) & 14,9 & 14,4 & 7,6 & 22,4 & 11,6 \\
\hline
\end{tabular}

TSA = testigo sin fertilización; $\mathrm{C} 19=19 \mathrm{t} \mathrm{ha}^{-1}$ de compost orgánico $\mathrm{C} 19+\mathrm{EM} 2=19 \mathrm{tha}^{-1}$ de compost orgánico + microorganismos eficientes al 2\% (EM2); $\mathrm{C} 15+\mathrm{B} 2=15 \mathrm{t} \mathrm{ha}^{-1}$ de compost orgánico $+2 \mathrm{t} \mathrm{ha}^{-1}$ de bokashi; EM2 $=$ microorganismos eficientes $2 \%$; $10=10 \mathrm{t} \mathrm{ha}^{-1}$ de bokashi; DMS = diferencia mínima significativa; $\mathrm{CV}=$ coeficiente de variación. Medias con la misma dentro de la columna son iguales por la prueba de Tukey $(\mathrm{p}<0,05)$. 


\section{Conclusiones}

La fertilización orgánica no afectó el crecimiento de plantas en el primer y segundo cultivo.

Fertilización exclusiva de compost y bokashi, aplicado solo o en conjunto promueven mayor materia fresca que plantas no fertilizadas en el primer cultivo.
EM potencia el efecto del compost, pues su aplicación conjunta estimula mayor materia fresca y materia seca que plantas no fertilizadas en el primer cultivo.

En los suelos con fertilidad media o alta, el compost aplicado solo o en conjunto con bokashi o EM sólo tiene efecto a corto plazo, pues no promovieron efecto residual en el segundo cultivo brócoli.

\section{Literatura Citada}

Alvarez, V.V.H.; Novais, R.F.D.; Barros, N.F.D.; Cantarutti, R.B.; Lopes, A.S.

1999. Interpretação dos resultados das análises de solos. In Recomendação para o uso de corretivos e fertilizantes em Minas Gerais - 5a aproximação, eds. Antonio Carlos Ribeiro, Paulo Tácito G. Guimarães and Victor Hugo Alvarez V., 25-32. Viçosa-MG: CFSEMG.

Barka, E.A.; Vatsa, P.; Sanchez, L.; Gaveau-Vaillant, N.; Jacquard, C.; Klenk, H.-P.; Clément, C.; Ouhdouch, Y.; Van Wezel, G.P. 2015. Taxonomy, Physiology, and Natural Products of Actinobacteria. Microbiology and Molecular Biology Reviews, 80: 1-43.

Bolívar-Anillo, H.J.; Contreras-Zentella, M.L.; TeheránSierra, L.G.

2016. Burkholderia tropica una bacteria con gran potencial para su uso en la agricultura. TIP Revista Especializada en Ciencias Químico-Biológicas, 19: 102-108.

Bonfim, F.P.G.; Honório, I.C.G.; Reis, I.L.; Pereira, A.D.J.; Souza, D.D.B.

2011. Caderno dos microrganismos eficientes (EM): instruções práticas sobre o uso ecológico e social do EM. http:// docplayer.com.br/1943867-Caderno-dos-microrganismoseficientes-em.html.

Calvo, P.; Nelson, L.; Kloepper, J.W.

2014. Agricultural uses of plant biostimulants. Plant and Soil, 383: 3-41.

Diniz, E.R.; Vargas, T.D.O.; Guedes, A.F.; Santos, R.H.S.;

Urquiaga, S.; Modolo, A.J.

2017. Doses of Crotalaria juncea: Residual effect on zucchini and maize crop in sequence to broccoli. Revista Ceres, 64: 600-606.

Diniz, E.R.; Vargas, T.O.; Santos, R.H.S.; Almeida, A.R.; Mattos, U.J.B.M.

2015. Crescimento e produção de brócolis adubado com doses de mucuna-cinza em casa de vegetação. Semina: Ciências Agrárias, 36: 1277-1286.

Diniz, I.C.C.; Matos, A.T.; Borges, A.C.; Aquino, J.M.G.L.;

Matos, M.P.

2016. Degradation of sewage sludge compost disposed on the soil. Engenharia Agricola, 36: 822-829.

Ferreira, S.; De Souza, R.J.; Gomes, L.a.A.

2013. Produtividade de brócolis de verão com diferentes doses de bokashi. Revista Agrogeoambiental, 5: 31-38.

Fontes, P.C.R.

1999. Sugestões de adubação para as diferentes culturas em Minas Gerais. Brócolos. In Recomendação para o uso de corretivos e fertilizantes em Minas Gerais: 5. Aproximação, eds. A.C. Ribeiro, P.T.G. Guimarães and V.H.V. Alvarez, 359. Viçosa: Comissão de Fertilidade do Solo do Estado de Minas Gerais.

Francescangeli, N.; Sangiacomo M.A.; Marti H.R.

2007. Vegetative and reproductive plasticity of broccoli at three levels of incident photosynthetically active radiation. Spanish Journal of Agricultural Research, 5: 389-401. DOI: $10.5424 /$ sjar/2007053-258.

Frasier, I.; Quiroga A.; Noellemeyer E.

2016. Effect of different cover crops on $\mathrm{C}$ and $\mathrm{N}$ cycling in sorghum NT systems. Science of The Total Environment, 562: 628-639.

Herencia, J.F.; Maqueda C.

2016. Effects of time and dose of organic fertilizers on soil fertility, nutrient content and yield of vegetables. Journal of Agricultural Science, 154: 1343-1361.

$\mathrm{Hu}, \mathrm{C} . \mathrm{Qi}$ Y.

2013. Long-term effective microorganisms application promote growth and increase yields and nutrition of wheat in China. European Journal of Agronomy, 46: 63-67.

Javaid, A.

2009. Growth, nodulation and yield of black gram [Vigna mungo (L.) Hepper] as influenced by biofertilizers and soil amendments. African Journal of Biotechnology, 8: 5711-5717.

Javaid, A.; Mahmood N.

2010. Growth, nodulation and yield response of soybean to biofertilizers and organic manures. Pakistan Journal of Botany, 42: 863-871.

Kaluzewicz, A.; Krzesinski W.; Knaflewski M.; Lisiecka J.; Spizewski T.; Fraszczak B.

2010. The effect of temperature on the broccoli yield and length of the period from head initiation to harvest. Acta Scientiarum Polonorum-Hortorum Cultus, 9: 167-174.

Ndona, R.K.; Friedel J.K.; Spornberger A.; Rinnofner T.; Jezik K. 2011. Effective micro-organisms' (EM): An effective plant strengthening agent for tomatoes in protected cultivation. Biological Agriculture \& Horticulture, 27: 189-204.

Santos, L.F.D.

2016. Micro-organismos Eficientes: diversidade microbiana e efeito na germinação, crescimento e composição química de capim-marandu. Programa de Pós-Graduação em Agroecologia, Universidade Federal de Viçosa.Viçosa Minas Gerais Brasil. 44.

Siddiqi, M.Y.; Glass A.D.M.

1981. Utilization index: A modified approach to the estimation and comparison of nutrient utilization efficiency in plants. Journal of Plant Nutrition, 4: 289-302. 
Suarez-Tapia, A.; Thomsen I.K.; Rasmussen J.; Christensen B.T.

2018. Residual N effect of long-term applications of cattle slurry using winter wheat as test crop. Field Crops Research, 221: 257-264.

Suthamathy, N.; Seran, T.H.

2013. Residual effect of Organic manure EM Bokashi applied to Proceeding Crop of Vegetable Cowpea (Vigna unguiculata) on succeeding Crop of Radish (Raphanus sativus). Research Journal of Agriculture and Forestry Sciences, 1: 2-5.

Tan, D.K.Y.; Birch C.J.; Wearing A.H.; Rickert K.G.

2000. Predicting broccoli development I. Development is predominantly determined by temperature rather than photoperiod. Scientia Horticulturae, 84: 227-243.

Vargas, T.D.O.; DinizE.R.; Pacheco A.L.V.; Santos R.H.S.; Urquiaga S.

2017. Green manure-15N absorbed by broccoli and zucchini in sequential cropping. Scientia Horticulturae, 214: 209-213. 